\title{
Femoral neck fracture prediction by anisotropic yield criteria
}

\author{
Mohamed Tellache*,** — Martine Pithioux* \\ Patrick Chabrand* - Christian Hochard**
}

\author{
* ISM, CNRS Université de la Méditerranée \\ 163 avenue de Luminy \\ F-13288, Marseille \\ ** LMA CNRS UPR 7051 \\ 31 chemin Joseph Augier \\ F-13009, Marseille
}

\begin{abstract}
The fracture risk due to osteoporosis, is undertaken with Dual-Energy X-ray Absorptiometry (DEXA) which is an average of bone mineral density measurement, without taking into account the bone structure. The objective of this study was an experimental test to solicit the human proximal femurs by a physiological configuration (one leg stance phase of walking). For this, transversely isotropic finite element models were developed from CT scan acquisition. The failure load assessment was insured by anisotropic yield behaviour criteria based on distortion energy criterion (Hill's criterion) and taking into account the difference between tension and compression yield properties (Tsai-Wu's criterion). The results found in this study showed the significance part of anisotropic yield behaviour of bone on proximal femur.

RÉSUMÉ. Le risque de fracture dû à l'ostéoporose est étudié avec la DEXA qui mesure la densité moyenne de l'os minéral en ne tenant pas compte de la structure osseuse. Le but de cette étude est un test expérimental visant à solliciter les fémurs proximaux humains avec une configuration physiologique (phase de marche monopodale). Pour cela, des modèles éléments finis isotropes transversaux on été développés à partir de CT scanner. L'estimation de la charge de rupture a été assurée par un critère de comportement anisotrope d'endommagement basé sur des critères d'énergie de distorsion (critères de Hill) et prenant en compte la différence entre la traction et la compression (critères de Tsai-Wu). Les résultats obtenus ont montré l'intérêt du comportement anisotrope d'endommagement de l'os sur le fémur proximal.
\end{abstract}

KEYWORDS: 3D-reconstruction, finite element model, anisotropic yield behaviour.

MOTS-CLÉS: reconstruction 3D, modèle éléments finis, comportement anisotrope d'endommagement.

DOI:10.3166/EJCM.18.33-41 @ 2009 Lavoisier, Paris

EJCM - 18/2009. Numerical models in biomechanics, pages 33 to 41 


\section{Introduction}

Osteoporosis is a worldwide health problem with about 1700 fractures per day only in Europe (World Health Organisation). Related to age, this disease weakens bone structure by deterioration of the trabecular architecture (Hajjar, and Kamel, 2004) and also decreases the cortical envelop width and increases its porosity (Bell el al., 1996). Hip fractures are the more recurrent consequences of osteoporosis, and are the cause of morbidity and increase the rate of mortality.

In spite of the important incidence on the public health, assessment of hip fracture risk is usually undertaken with Dual-Energy X-ray Absorptiometry (DEXA), but this has the limitation that only the integral bone mass and the areal bone density (grams per square centimeter) can be measured, without taking into account the bone structure.

In order to improve the assessment of fracture risk, investigators have turned to develop non-invasive methods based on densitometric properties of human bone (Lockmüller et al., 2002), geometric and structural engineering properties of human proximal femur (Beck et al., 1990). These techniques have been somewhat successful, but their precision for estimating fracture load and identifying subjects with high fracture risk is limited by their inability to take into account the complex geometry, heterogeneity, and anisotropic behaviour of human bone.

In order to obtain more sophisticated evaluations of fracture load, finite element models were developed in mechanical study of proximal femur. The finite element models used linear analysis to assess the stress distribution under physiologic loading, in bone tissue (Lotz et al., 1991a), or non linear models of bone behaviour to evaluate fracture loads (Lotz et al., 1991b, Keyak et al., 2002). Those models don't take into account either the orthotropic behaviour of human bone (Pithioux M., 2000) or the anisotropic yield behaviour of human (Cezayirlioglu et al., 1985).

Our aim was to develop an experimental test to solicit the human proximal femurs by a physiological configuration (one leg stance phase of walking) and to analyse the contribution of both cortical envelop and trabecular bone in the strength of femur structure. For this, transversely isotropic finite element models were developed from CT scan acquisition. The failure load assessment was insured by anisotropic yield behaviour criteria based on distortion energy criterion (Hill's criterion) and taking into account the difference between tension and compression yield properties (Tsai-Wu's criterion).

\section{Material}

The study involved 3 proximal femurs of human donors obtained from the Anatomy laboratory of La Timone Hospital, Marseilles. The Femurs conservation was insured by Winkler injection and a $-20{ }^{\circ} \mathrm{C}$ freezing. CT scan of femurs was performed by helicoid scanner acquisition with $0,625 \mathrm{~mm}$ native cuts thickness 
(General Electric LightSpeed Pro 16, $140 \mathrm{Kv}$; Medical imagery service of LaTimone hospital, Marseilles).

For testing in one leg stance position, femurs were fixed by an Epoxy resin device designed in PVC sleeves with respect of physiological orientations in both sagital and frontal planes. This device allowed to adapt femurs to vertical loading (Figure 1). The mechanical testing was performed by an INSTRON machine equipped with cell load (measure loads going up to $1000 \mathrm{daN} \pm 2.5 \mathrm{~N}$ ), under quasi-static load with a controlled displacement $(2 \mathrm{~mm} / \mathrm{min})$. The load was applied on femora heads with an indenter equipped with an elastomer ring for a better repartition of load within contact surface.

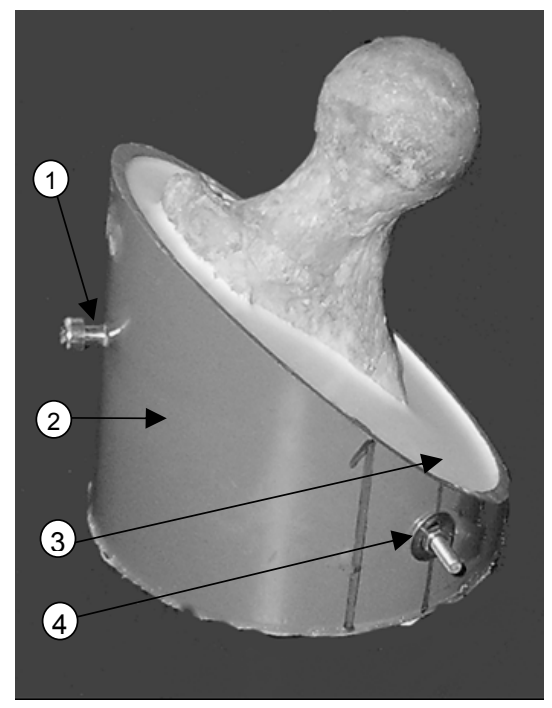

Figure 1. Fixation device of proximal femur: 1-screw 2-PVC sleeve 3-Epoxy resin F1 4-Treaded rod

The CT scan was used to generate voxel finite element model by CT2FEM (CT2FEM, 1996). This method allows to assign to each generated voxel, a density described by grey level from CT scans. Thus, each element has an effective bone density. The apparent density of the bone was calculated according to the method described by Taylor et al., (2002).

Two separated tissues were considered in the model, cortical bone and cancellous bone. The cortical bone was separated from the cancellous bone by apparent density threshold. For an apparent density greater than $0.2 \mathrm{~g} / \mathrm{cm} 3$, the bone was considered cortical; under it was considered cancellous (Bessho et al., 2006). 


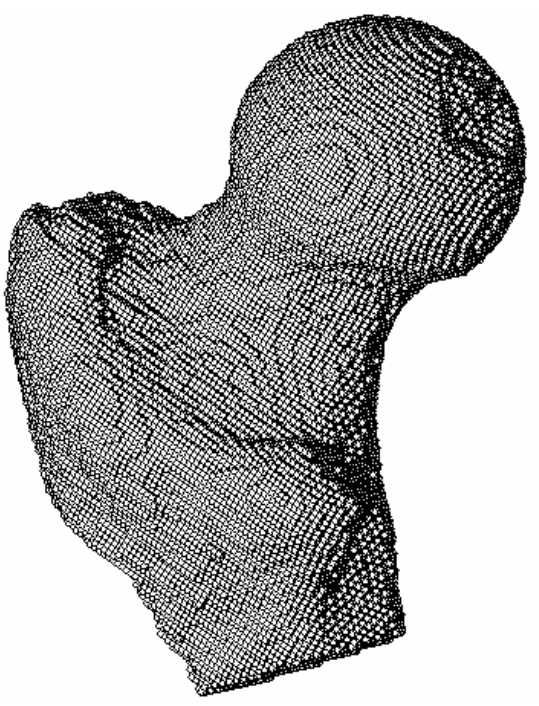

Figure 2. Voxel based mesh model of the first femur

The cortical bone was considered transversely isotropic (Huiskes et al., 1981, Katz and Meunier, 1987, Pithioux, 2000). In this model, the cortical bone elastic properties were calculated from density by a power law described by Keyak et al., 2005. The grey level reported in scanners was related to apparent density by a linear interpolation. The apparent density was then used to calculate the Young modulus in principal direction for cortical bone (Equation [1]).

$$
E_{1, k}=14900 \rho_{a p p, k}^{1,86}
$$

Moreover, the elastic properties of the $\mathrm{k}^{\text {th }}$ element in the other direction $\left(\mathrm{E}_{i ; k}\right.$; $\left.\mathrm{G}_{i j ; k}\right)$, were given function of the calculated Young modulus in the principal direction $\left(E_{i ; k}\right)$ according to experimental data (Pithioux, 2002).

$$
E_{2, k}=E_{3, k}=0.6 E_{1, k} ; G_{12, k}=G_{13, k}=0.25 E_{1, k}
$$

The cortical bone was considered brittle with difference in tension and compression. The longitudinal yield limit in compression was correlated to apparent density with Keyak's power relation described in Equation [2] (Keyak et al., 2005).

$$
\sigma_{1, k}^{C}=102 \rho_{a p p, k}^{1,86}
$$

By the same way, yield limits of the $\mathrm{k}^{\text {th }}$ element and $\mathrm{i}^{\text {th }}$ direction, in tension, compression and shear, were given by empiric correlation according to experimental data reported by Pithioux, (2002). 


$$
\sigma_{i, k}^{C}=2 \sigma_{i, k}^{T} ; \sigma_{2, k}^{C}=\sigma_{3, k}^{C}=0.6 \sigma_{1, k}^{C} ; \sigma_{i j, k}=0.25 \sigma_{i, k}^{C}
$$

The cancellous bone was assumed to present a large-scale isotropy (Brown and Ferguson, 1980), with strong variability according to studied region. This variation is strongly dependant on the orientation of trabeculae. In this model, the spongy part was considered isotropic and its elastic modulus was calculated from bone mineral density by the Keyak's power law (Equation [1]). The value of Poisson coefficient $(v=0.3)$ was taken from experimental data (Black and Hastings, 1998).

$$
E_{k}=14900 \rho_{a p p, k}^{1,86}
$$

The boundary condition and load case represent the experimental conditions. The load was applied to a restricted region of the femoral head as in mechanical tests according to Yoshida et al. 2002. The governing equations of the model were solved using standard finite element method (ABAQUS, Hibbitt, Karlsson and Sorensen, Inc.).

The failure load $\left(f_{F E}\right)$ was predicted by failure criteria and compared to experimental results. The failure occurs when an element reach a limit define by a stress function. The general form of failure function is

$$
f\left(\sigma_{i j}^{k}\right) \geq 1
$$

In this model, the Hill and the Tsai-Wu criteria were used. The first is an extention to orthotropic materials of Von-Mises failure criteria, the second is an extension of Hill criteria taking into account the difference in compression and tension behaviour of cortical bone.

The general form of the Hill criteria for the $k^{\text {th }}$ element, in case of transversely isotropic material is

$$
\begin{gathered}
f(\sigma)=\left[F\left(\left(\sigma_{y y}^{k}-\sigma_{x x}^{k}\right)^{2}+\left(\sigma_{z z}^{k}-\sigma_{x x}^{k}\right)^{2}\right)+H\left(\sigma_{y y}^{k}-\sigma_{z z}^{k}\right)^{2}+\right. \\
\left.+2 L\left(\left(\tau_{x y}^{k}\right)^{2}+\left(\tau_{x z}^{k}\right)^{2}\right)+2 N\left(\tau_{y z}^{k}\right)^{2}\right]^{1 / 2}
\end{gathered}
$$

Where $\sigma_{i j}^{k}$ are the stress components $k^{\text {th }}$ elment and $F, H, L$ and $N$ are coefficients calculated from yield limits of this element.

$$
\begin{aligned}
& 2 F=1 /\left(\sigma_{1, k}^{C}\right)^{2} ; 2 H=2 /\left(\sigma_{2, k}^{C}\right)^{2}-1 /\left(\sigma_{1, k}^{C}\right)^{2} ; \\
& 2 L=1 /\left(\sigma_{12, k}\right)^{2} ; 2 N=1 /\left(\sigma_{23, k}\right)^{2}
\end{aligned}
$$


The general form for the Tsai-Wu criteria for transversely isotropic material is

$$
\begin{aligned}
& f(\sigma)=\left[F_{1} \sigma_{x x}^{k}+F_{2}\left(\sigma_{y y}^{k}+\sigma_{z z}^{k}\right)+F_{11}\left(\sigma_{x x}^{k}\right)^{2}+F_{22}\left(\left(\sigma_{y y}^{k}\right)^{2}+\left(\sigma_{z z}^{k}\right)^{2}\right)+\right. \\
& \left.+F_{66}\left(\tau_{y z}^{k}\right)^{2}+F_{44}\left(\left(\tau_{x y}^{k}\right)^{2}+\left(\tau_{x z}^{k}\right)^{2}\right)+2 F_{12}\left(\sigma_{x x}^{k} \sigma_{y y}^{k}+\sigma_{x x}^{k} \sigma_{z z}^{k}\right)+2 F_{23} \sigma_{y y}^{k} \sigma_{z z}^{k}\right]^{1 / 2}
\end{aligned}
$$

Where $F_{1} ; F_{2} ; F_{11} ; F_{22} ; F_{44} ; F_{66}$ are coefficients calculated from yield limits of $k^{\text {th }}$ element and $F_{12} ; F_{23}$ are determined experimentally. In this model, they were accepted to be equal to zero.

$$
\begin{gathered}
F_{1}=1 / \sigma_{1, k}^{T}-1 / \sigma_{1, k}^{C} ; F_{2}=1 / \sigma_{2, k}^{T}-1 / \sigma_{2, k}^{C} ; \\
F_{11}=1 /\left(\sigma_{1, k}^{T} \sigma_{1, k}^{C}\right) ; F_{22}=1 /\left(\sigma_{2, k}^{T} \sigma_{2, k}^{C}\right) ; \\
F_{44}=1 / \sigma_{12, k}^{2} ; F_{66}=1 / \sigma_{23, k}^{2}
\end{gathered}
$$

\section{Results}

The three femurs sustained a sub-capital neck fracture with a vertical bifurcation after rupture (Figure 3). The failure force was $256 \mathrm{daN}$ for the femur-1, 300daN for the femur-2 and was $466 \mathrm{daN}$ for femur-3.
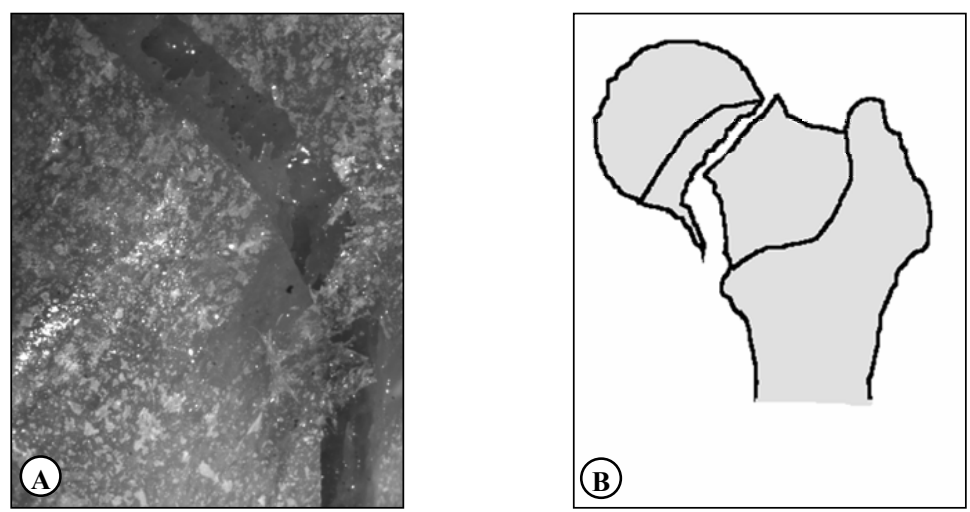

Figure 3. Rupture profiles obtained. (A) Rupture line of femur-1observed by photo acquisition system. (B) Schema of femur-1, femur-2 and femur-3 rupture profile

The predicted failure loads estimated by Hill failure criteria was $227 \mathrm{daN}$ for femur-1, $368 \mathrm{daN}$ for femur-2 and $678 \mathrm{daN}$ for femur-3. The Tsai-Wu failure criteria estimation was $244 \mathrm{daN}$ for femur-1, $248 \mathrm{daN}$ for femur-2 and $483 \mathrm{daN}$ for femur-3. Figure 4 shows a comparison between experimental and numerical failure loads. 


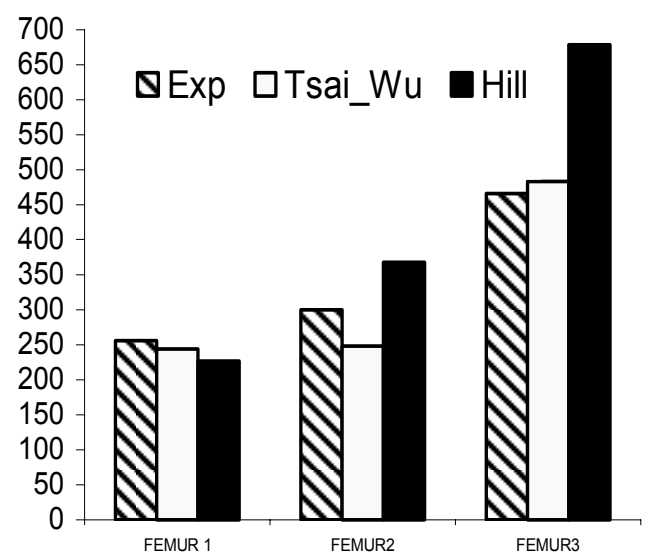

Figure 4. Experimental and numerical failure loads comparison (daN)

The location of the first element with reached failure limit in both failure criteria was in femoral neck. For femur-1, the element was located in superior face of cortical neck bone, at sub-capital section. For the femur-2 and femur-3, the element was located in inferior face of cortical neck bone, in cervical section (Figure 5).
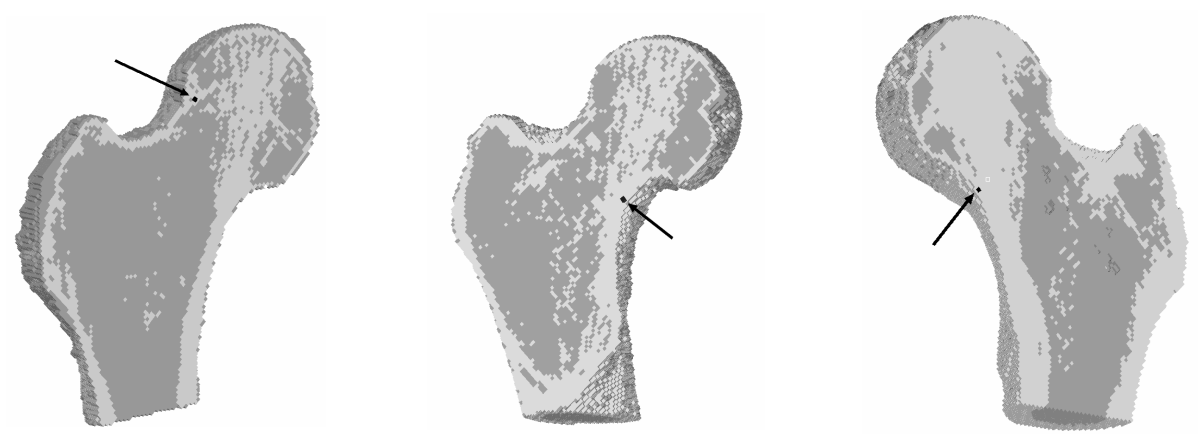

Figure 5. Location of the first element with reached failure limit

\section{Discussion}

The goal of this study was to assess the power of anisotropic failure criteria to predict fracture load of the proximal femur. For this, the strength of three femurs was measured in-vitro by an original test, designed to simulate one leg stance of human walking. The results obtained were comparable with those obtained in vertical loading by Lochmüller (442 $\pm 168 \mathrm{daN}$ for men, $291 \pm 93 \mathrm{daN}$ for women). 
Moreover, the rupture profiles obtained in this experience were close to the clinically observed fractures (sub-capital neck fractures, see Figure 3).

The finite element models used were CT scan based models which elastic properties were directly related to grey level observed in scans. The cortical bone was considered transversly isotropic to better simulate the orthotropic behaviour of human bone (Pithioux, 2000). Furthermore, the failure criteria used were designed for orthotropic materials, Hill's criterion, with anisotropic yield behaviour TsaiWu's criterion. For the first femur, the Tsai-Wu's and the Hill's criteria have the same prediction of failure. For the second and the third femur, the Tsai-Wu's criterion was more predictive than the Hill's criterion. In comparable study, Keyak et al., 2000, found that the Von-Mises's criterion was the most robust in failure prediction. In spite of the fact that the Hill's criterion is an extension to orthotropic materials of the Von Mises's criterion, we have shown that the recognition of the difference between compression and tension behaviour of human cortical bone in the Tsai-Wu's criterion, gave better prediction of failure load. In both criteria, the first element reaching the failure limit was located in cortical envelop of the femoral neck, as observed experimentally in similar section.

The results found in this study show the significance part of anisotropic yield behaviour of bone on proximal femur strength and appear in agreement with the results found by Cezayirlioglu et al., 1985 for cortical bone samples under combined loading.

Finally, the present work shows the results of three femurs. In further study six other femurs tested under the same configurations will be added to the present results. Moreover, to improve the accuracy of the criteria models, an experimental identification of Tsai-Wu's criterion coefficient by combined testing of cortical bone samples may improve the rupture prediction.

\section{Acknowledgements}

The authors want to thank Professor P. Champsaur and Doctor T. LeCorroller (Anatomy laboratory of medicine faculty, Mediterranean university) for having provided the bones and realized tomography acquisitions. We also thank S. Seguinel for her assistance in the drafting of this paper.

\section{References}

Bell K. L., Garrahan N., Kneissel M., Loveridge N., Grau E., Stanton M., Reeve J., "Cortical and Cancellous Bone in the Human Femoral Neck: Evaluation of an Interactive Image Analysis System", Bone, vol. 19, n 5, November 1996, p. 541-548.

Bessho M., Ohnishi I., Matsuyama J., Matsumoto T., Imai K., Nakamura K., "Prediction of strength and strain of the proximal femur by a CT-based finite element method", Journal of Biomechanics, vol. 40, $\mathrm{n}^{\circ}$ 8, 2007, p. 1745-1753. 
Black J., Hastings G., Handbook of Biomaterial properties, Chapman et Hall, London, 1998.

Brown T.D., Ferguson A.B.J., "Mechanical property distributions in the cancellous bone of the human proximal femur", Acta Orthopaedica Scandinavica, vol. 51, 1980, p. 429-437.

Cezayirlioglu H., Bahniuk E., Davy D. T., Heiple K. G., “Anisotropic yield behavior of bone under combined axial force and torque", Journal of Biomechanics, vol. 18, 1985, p. 61-69.

CT2FEM: Copyright (c) 1996 Laboratorio di Tecnologia Medica of Istituti Ortopedici Rizzoli, Bologna - Italy.

Hajjar R.R., and Kamel H. K., "Osteoporosis for the Home Care Physician, Part 1: Etiology and Current Diagnostic Strategies", Journal of the American Medical Directors Association, vol. 5, n 3, May-June 2004, p. 192-196.

Huiskes R., Janssen J.D., Slooff, T.J., "A detail comparison of experimental and theoretical stressanalyses of a human femur", Mechanical properties of Bone, vol. 45, 1981, p. 211-234.

Katz J.L., Meunier A., "The elastic anisotropy of bone”, Journal of Biomechanics, vol. 20, 1987, p. 1063-1070.

Keyak J. H., Rossi S. A., "Prediction of femoral fracture load using finite element models: an examination of stress-and strain-based failure theories", Journal of Biomechanics, vol. 33, 2000, p. 209-214.

Keyak J. H., Kaneko, T. S., Tehranzadeh J., Skinner H.B., "Predicting proximal femoral strength using structural engineering models", Clin Orthop Relat Res, 2005, p. 219-28.

Lochmüller E.M., Groll O., Kuhn V., Eckstein F., "Mechanical strength of the proximal femur as predicted from geometric and densitometric bone properties at the lower limb versus the distal radius", Bone, vol. 30, 2002, p. 207-216.

Lotz J.C., Cheal E.J., Hayes W.C., "Fracture prediction for the proximal femur using finite element models: Part I — Linear analysis", J. Biomech Eng, vol. 60, 1991, p. 113-353.

Lotz J.C., Cheal E.J., Hayes W.C., "Fracture prediction for the proximal femur using finite element models: Part II — Nonlinear analysis", J. Biomech Eng, vol. 5, 1991, p. 113-361.

Pithioux M., Lois de comportement et modèles de rupture des os long. Thèse de doctorat, Université d'Aix Marseille II, 2000.

Taylor W.R., Roland E., Ploeg H., Hertig D., Klabunde R., Warner M.D., Hobatho M.C., Rakotomanana L., Clift S.E., "Determination of orthotropic bone elastic constants using FEA and modal analysis", J. Biomech, vol. 35, 2002, p.767-773.

Yoshida H., Faust A., Wilckens J., Kitagawa M., Fetto J., Chao E.Y., “Three-dimensional dynamic hip contact area and pressure distribution during activities of daily living", $J$. Biomech, vol. 39, 2005, p. 1996 - 2004. 24. 
